\title{
Cytochrome $b$ sequence analysis reveals differential molecular evolution in African mole-rats of the chromosomally hyperdiverse genus Fukomys (Bathyergidae, Rodentia) from the Zambezian region
}

\author{
Paul A.A.G. Van Daele ${ }^{\mathrm{a}, *}$, E. Verheyen ${ }^{\mathrm{b}}$, M. Brunain ${ }^{\mathrm{a}}$, D. Adriaens ${ }^{\mathrm{a}}$ \\ ${ }^{a}$ Ghent University, Evolutionary Morphology of Vertebrates, K.L. Ledeganckstraat 35, B-9000 Ghent, Belgium \\ ${ }^{\mathrm{b}}$ Royal Belgian Institute of Natural Sciences, Vautierstraat 29, B-1000 Brussels, Belgium
}

Received 23 November 2006; revised 16 March 2007; accepted 9 April 2007

Available online 21 April 2007

\begin{abstract}
African mole-rats (Bathyergidae, Rodentia) of the (eu)social genus Fukomys are one of the most speciose mammal genera endemic to Sub-Saharan Africa. Fukomys distributed in the Zambezian phytochorion is characterized by extreme chromosomal variation $(2 \mathrm{n}=40$ 78). We inferred a molecular phylogeny of Zambezian Fukomys to resolve the interrelationships and the evolutionary history of the known chromosomal races. We sequenced the entire cytochrome b gene (1140 bp) for a total of 66 specimens representing 18 karyotypical races from Zambia. An additional 31 sequences were retrieved from GenBank including data on all other chromosomal races. The haplotypes belonging to a small chromosomal race from Salujinga cluster with the Fukomys mechowii (Giant mole-rat) haplotypes. Differential degrees of chromosomal variation are observed among the major mole-rat clades, which is most pertinent when comparing the central Zambezian Fukomys micklemi and the northern Zambezian Fukomys whytei clades. The karyotypically hyper-diverse (12 known chromosomal races) Fukomys micklemi clade shows low levels of cytochrome b sequence divergence. Within the $F$. whytei clade we find a more conservative pattern of chromosomal diversification (three known chromosomal races) while the levels of sequence divergence are much higher then in the $F$. micklemi clade. Our results suggest that chromosomal changes may drive phyletic divergence and, eventually, speciation. The observed cladogenetic events during the Plio-Pleistocene within the F. mechowii, F. whytei, F. damarensis and F. micklemi clades appear to coincide with climatically mediated speciation bursts in other savannah dwelling mammals, including hominids. Based on the molecular data presented, combined with morphological and chromosomal data, the taxonomic implication seems to be that Fukomys may contain several (undescribed) cryptic species.
\end{abstract}

(C) 2007 Elsevier Inc. All rights reserved.

Keywords: Cryptomys; Fukomys; Mitochondrial DNA; Cytochrome b; Molecular phylogeny; Chromosome races

\section{Introduction}

\subsection{A recently described genus of social mole-rats}

Fukomys (Rodentia: Bathyergidae-African mole-rats) represents one of the most speciose rodent genera. The genus encompasses several species of subterranean rodents that are endemic to Sub-Sahara Africa. It is the most

\footnotetext{
${ }^{*}$ Corresponding author. Fax: +3292645344.

E-mail address: paul.vandaele@ugent.be (P.A.A.G. Van Daele).
}

derived lineage within the Bathyergidae comprising several social and at least one eusocial species (Fukomys damarensis). The varying degree of sociality is negatively correlated with precipitation, which subsequently influences the distribution of geophytes, the animals' staple food (Jarvis et al., 1994). The causes of social evolution in bathyergids, however, are still debated (Bennett and Faulkes, 2000; Burda et al., 2000). While Fukomys has been vilified for damaging crops, it is an important food resource for humans in many parts of its geographic range. Recently, several research groups have succeeded in maintaining and breeding the 
animals in captivity, which will facilitate research in many different aspects of the biology of these mammals, including genetics, chromosomal evolution, evolution of sociality, ethology, biogeography, morphology, ecophysiology and sensory biology (e.g. Jarvis and Bennett, 1993; Bruckmann and Burda, 1997; Jarvis et al., 1998; Spinks et al., 2000a,b; Faulkes and Bennett, 2001; Nemec et al., 2001; Faulkes et al., 2004; Van Daele et al., 2004; Janse Van Rensburg et al., 2004; Scantlebury et al., 2006; Dammann and Burda, 2006). Furthermore, Fukomys is the subject of an increasing number of studies that investigate the mole-rats' behaviour and ecology (e.g. Hazell et al., 2000; Greeff and Bennett, 2000; Burland et al., 2002, 2004; Barnett et al., 2003; Ganem and Bennett, 2004). It may be expected that, in addition to the confamiliar naked molerat (Heterocephalus glaber), this group of African mole-rats will be of particular interest for gerontological research, taking into account longevity quotients similar to those of humans (Buffenstein, 2005; Dammann and Burda, 2006) combined with the differential levels of chromosomal and mitochondrial DNA sequence divergence, which is emphasized by the sequences available to date (Faulkes et al., 1997, 2004; Ingram et al., 2004; this paper).

\subsection{Phylogenetic analyses, chromosomal diversification and classification}

Given the fact that Bathyergidae are one of the best studied rodent groups in Africa, the systematics and phylogeny of this family have been addressed by other studies (reviewed in Van Daele et al., 2007). Fukomys is the most recently recognised member of the six genera that constitute the Bathyergidae. Fukomys (synonym Coetomys nomen invalidus; Kock et al., 2006) forms a northern clade within a phylogroup (Cryptomys sensu lato) that further contains the reciprocally monophyletic Cryptomys sensu stricto clade of southern Africa. Two recent phylogenetic analyses using nuclear and mitochondrial DNA sequences, combined with data on chromosomal variation, unambiguously support the taxonomic division of Cryptomys and Fukomys, although these data do not resolve the relationships within Fukomys (Faulkes et al., 2004; Ingram et al., 2004). To date no less than 12 Fukomys species are accepted as valid. In a taxonomic revision Honeycutt et al. (1991) retained 6 species: Fukomys bocagei (De Winton, 1897), F. damarensis (Ogilby, 1838), F. foxi (Thomas, 1911), Fukomys mechowii (Peters, 1881), F. ochraceocinereus (Heuglin, 1864), and F. zechi (Matschie, 1900). Subsequent allozyme and karyological studies (Aguilar, 1993; Macholán et al., 1998; Filippucci et al., 1994; Burda et al., 1999; Chitaukali et al., 2001; Van Daele et al., 2004; Burda et al., 2005) demonstrated the specific status of Fukomys amatus (Wroughton, 1907), Fukomys anselli (Burda et al., 1999), Fukomys darlingi (Thomas, 1895), Fukomys kafuensis (Burda et al., 1999), F. micklemi (Chubb, 1909) and F. whytei (Thomas, 1897). Fukomys mole-rats are a complex of morphologically very similar species that can not be readily diagnosed due to the low resolution of the known morphological markers.

However, variation in diploid number in this clade is known to be among the highest among mammals, as opposed to the karyotypically conserved sisterclade Cryptomys sensu stricto (Burda, 2001). Furthermore, Van Daele et al. (2004) recently described 9 new chromosomal races within the Zambezian clade (i.e. the mechowi (sic) group of Ingram et al., 2004), illustrating that south-central Zambia forms a "hotspot of karyotypical diversity". The evolutionary mechanisms behind chromosomal diversity within Fukomys remain poorly understood. The mainly allopatric distribution of the known chromosomal races that occur throughout the Zambezian phytochorion is consistent with a scenario of vicariance events, driven by major geomorphological reconfigurations in the Zambezian area (Van Daele et al., 2004; Cotterill, 2003). The observed absence of morphological differentiation accompanied with a high level of chromosomal diversity underpins the need for a systematic revision of these mammals, as well as a molecular phylogeographic approach to infer the evolutionary histories and interrelationships of these putative taxa and their populations.

Using mitochondrial cytochrome b (cyt b) sequences we aim to clarify the interrelationships and evolutionary history of the known chromosomal races. The combination of molecular and chromosomal data allows further exploration of the role of chromosomal evolution in the speciation of these small mammals. Are we to expect equal levels of genetic divergence between chromosomal races within different clades, as might be anticipated in view of the comparable range of diploid numbers in e.g. northern and southern Zambezian lineages? This study provides the most comprehensive sampling of this taxon so far, by increasing the number of studied chromosomal races and extending the sampling area in comparison with earlier studies. The choice of the mitochondrial cytochrome $\mathrm{b}$ locus was based on the facts that 1 . due to its higher mutation rate compared with most nuclear DNA, it is known to be useful for the inference of relationships among closely related mammal species and populations, and 2. previously published sequences could be included in our analyses.

\section{Materials and methods}

\subsection{Sampling strategy: topotypical approach}

Specimens of Fukomys were sampled throughout their distribution in Zambia and Malawi between 1987 and 2002 (Fig. 1). All specimens collected at type localities are tentatively given the corresponding species name. However, species names are not provided for any of the other specimens due to the low resolution of the diagnostic morphological characters. The samples comprise the topotypes of all chromosomal races (underlined) that hitherto have been described as well as specimens collected from a 


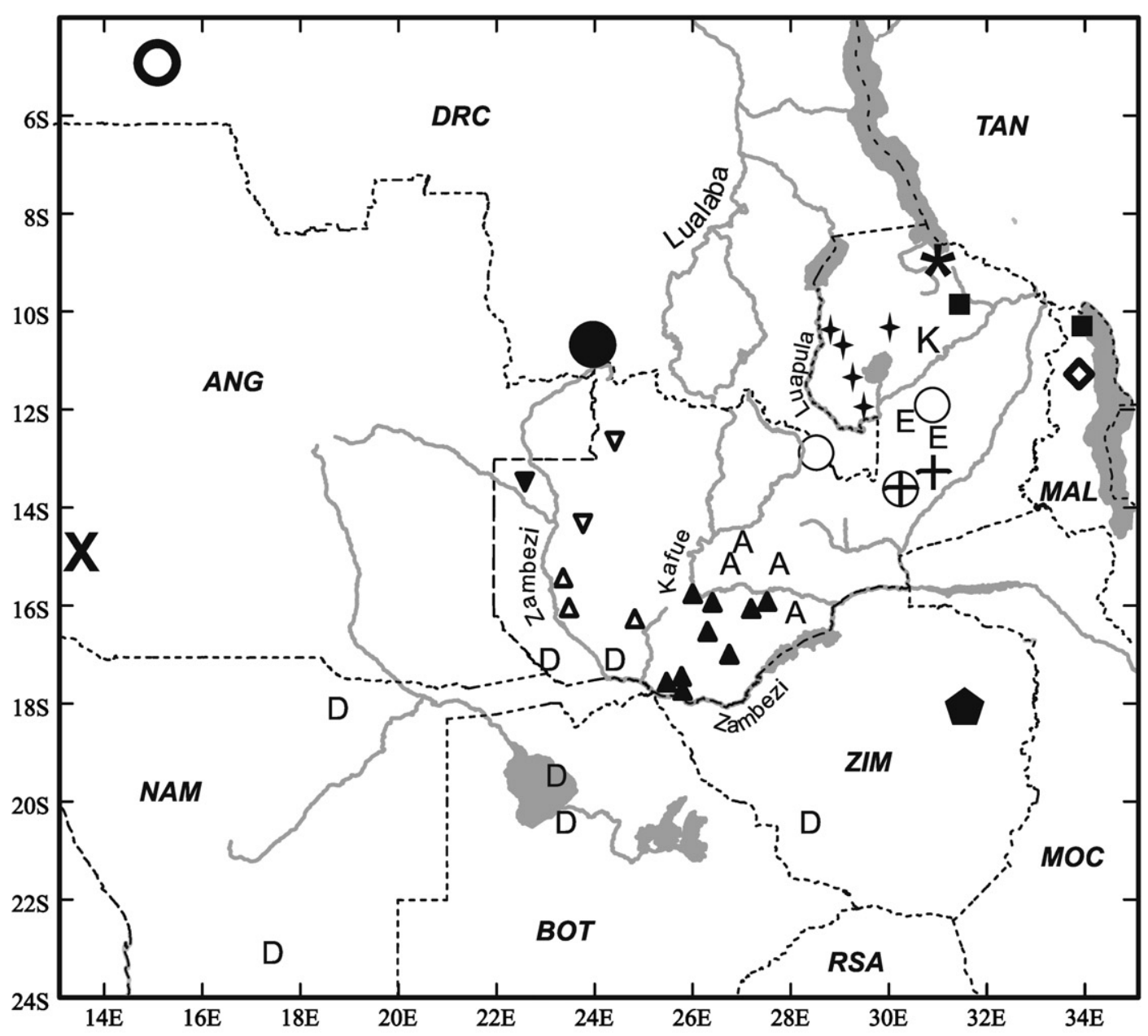

\section{LEGEND}
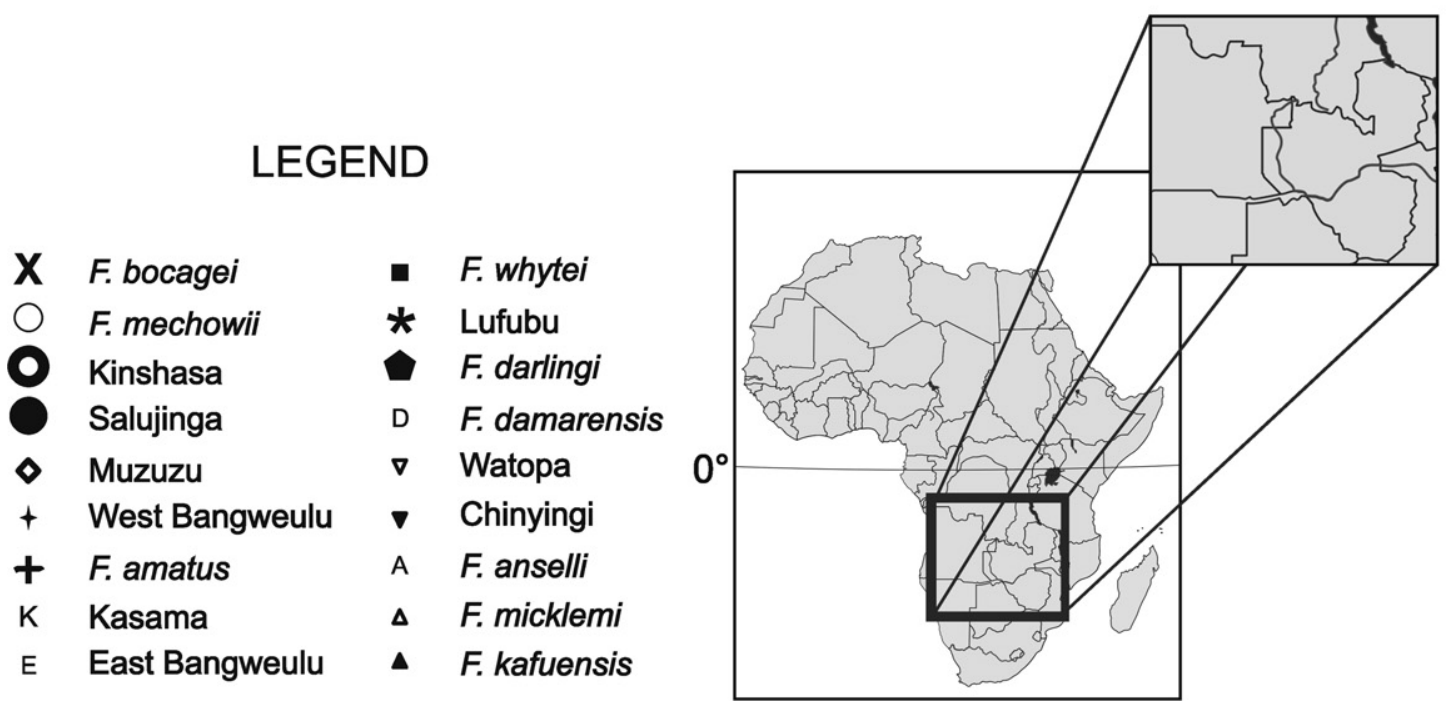

Fig. 1. Sampling localities in Zambia and neighbouring countries.

number of type localities (marked with *). Thus, our present data set includes data from all described species and chromosomal races in the genus (see above). From the total of 97 samples, sequence data of 66 samples are previously unpublished. This includes data from 27 new localities (Table 1).

\subsection{DNA isolation, PCR amplification and nucleotide sequencing}

PriortoDNAextraction, tissue(liver)waspreservedineither $70 \%$ ethanol(University of Duisburg-Essen collection) or $95 \%$ ethanol (Ghent University collection) and stored at $-20{ }^{\circ} \mathrm{C}$. 
Table 1

Specimens sequenced with their respective clade, geographic location and GenBank Accession Numbers

\begin{tabular}{|c|c|c|c|c|c|}
\hline Clade & $\mathrm{N}$ & Location and country & Lat $(\mathrm{S})$ & Lon $(\mathrm{E})$ & GenBank No. \\
\hline mechowii & 1 & Chiundaponde, Zambia $^{*}$ & $12^{\circ} 14^{\prime}$ & $30^{\circ} 35^{\prime}$ & EF043451 \\
\hline mechowii & 1 & Chibale, Zambia & $13^{\circ} 35^{\prime}$ & $30^{\circ} 05^{\prime}$ & EF043452 \\
\hline mechowii & 1 & Mbombo-Lumene NP (near Kinshasa), DRC & $04^{\circ} 22^{\prime}$ & $15^{\circ} 27^{\prime}$ & $\mathrm{AF} 012231$ \\
\hline mechowii & 1 & Chingola, Zambia & $12^{\circ} 31^{\prime}$ & $27^{\circ} 51^{\prime}$ & AF012230 \\
\hline mechowii & 3 & Salujinga, Zambia & $10^{\circ} 58^{\prime}$ & $24^{\circ} 05^{\prime}$ & EF043453-EF043455 \\
\hline bocagei & 1 & Lubango, Angola & $14^{\circ} 56^{\prime}$ & $13^{\circ} 27^{\prime}$ & AF012229 \\
\hline whytei & 5 & Kasanka, Zambia & $12^{\circ} 08^{\prime}$ & $29^{\circ} 47^{\prime}$ & EF043456- EF043460 \\
\hline whytei & 1 & Kambi, Zambia & $11^{\circ} 30^{\prime}$ & $29^{\circ} 34^{\prime}$ & EF043461 \\
\hline whytei & 1 & Kane, Zambia & $10^{\circ} 33^{\prime}$ & $28^{\circ} 59^{\prime}$ & EF043462 \\
\hline whytei & 1 & n. Kakululu River, Zambia & $10^{\circ} 38^{\prime}$ & $29^{\circ} 04^{\prime}$ & EF043463 \\
\hline whytei & 1 & Chief Tungati Local Forest, Zambia & $10^{\circ} 27^{\prime}$ & $30^{\circ} 00^{\prime}$ & EF043464 \\
\hline whytei & 1 & Kama, Zambia & $12^{\circ} 24^{\prime}$ & $30^{\circ} 21^{\prime}$ & EF043465 \\
\hline whytei & 2 & Chinsobwe, Zambia & $13^{\circ} 23^{\prime}$ & $30^{\circ} 21^{\prime}$ & EF043466- EF043467 \\
\hline whytei & 1 & Chibale, Zambia ${ }^{*}$ & $13^{\circ} 35^{\prime}$ & $30^{\circ} 05^{\prime}$ & EF043468 \\
\hline whytei & 1 & Mushangashi, Zambia & $12^{\circ} 28^{\prime}$ & $30^{\circ} 23^{\prime}$ & EF043469 \\
\hline whytei & 2 & South of Lake Chiwakawaka, Zambia & $12^{\circ} 32^{\prime}$ & $30^{\circ} 37^{\prime}$ & EF043470-EF043471 \\
\hline whytei & 1 & Ndeba1, Zambia & $12^{\circ} 26^{\prime}$ & $30^{\circ} 39^{\prime}$ & EF043472 \\
\hline whytei & 1 & Ndeba2, Zambia & $12^{\circ} 28^{\prime}$ & $30^{\circ} 38^{\prime}$ & EF043473 \\
\hline whytei & 1 & Kasama, Zambia ${ }^{*}$ & $10^{\circ} 16^{\prime}$ & $31^{\circ} 00^{\prime}$ & EF043474 \\
\hline whytei & 2 & Lufubu, Zambia* & $09^{\circ} 15^{\prime}$ & $30^{\circ} 53^{\prime}$ & EF043475-EF043476 \\
\hline whytei & 1 & Karonga, Malawi* & $09^{\circ} 56^{\prime}$ & $33^{\circ} 56^{\prime}$ & EF043477 \\
\hline whytei & 3 & Mbala, Zambia & $09^{\circ} 50^{\prime}$ & $31^{\circ} 24^{\prime}$ & AY425860-AY425862 \\
\hline whytei & 1 & Suma, Tanzania & $09^{\circ} 10^{\prime}$ & $33^{\circ} 40^{\prime}$ & AY425859 \\
\hline whytei & 1 & Mzuzu, Malawi & $11^{\circ} 27^{\prime}$ & $34^{\circ} 03^{\prime}$ & AY425863 \\
\hline darlingi & 1 & Goromonzi, Zimbabwe & $17^{\circ} 52^{\prime}$ & $31^{\circ} 30^{\prime}$ & AF012232 \\
\hline damarensis & 2 & Simungoma, Zambia & $22^{\circ} 49^{\prime}$ & $38^{\circ} 57^{\prime}$ & EF043478-EF043479 \\
\hline damarensis & 2 & Sioma Ngwezi N.P., Zambia & $31^{\circ} 33^{\prime}$ & $19^{\circ} 36^{\prime}$ & EF043480-EF043481 \\
\hline damarensis & 1 & Maun, Botswana & $19^{\circ} 59^{\prime}$ & $23^{\circ} 21^{\prime}$ & AF012221 \\
\hline damarensis & 4 & Okavango, Botswana & $19^{\circ} 32^{\prime}$ & $23^{\circ} 11^{\prime}$ & AF012220-AF12224 \\
\hline damarensis & 1 & Bulawayo, Zimbabwe & $20^{\circ} 09^{\prime}$ & $28^{\circ} 38^{\prime}$ & AY425857 \\
\hline damarensis & 3 & Dorbabis, Namibia & $22^{\circ} 58^{\prime}$ & $17^{\circ} 41^{\prime}$ & AF012225 \\
\hline damarensis & 1 & Rundu, Namibia & $17^{\circ} 48^{\prime}$ & $19^{\circ} 32^{\prime}$ & AY425858 \\
\hline damarensis & 3 & Hotazel, South Africa & $27^{\circ} 17^{\prime}$ & $23^{\circ} 00^{\prime}$ & AY425853-AY425855 \\
\hline micklemi & 1 & Chinyingi, Zambia & $13^{\circ} 23^{\prime}$ & $23^{\circ} 00^{\prime}$ & EF043482 \\
\hline micklemi & 2 & Mayau, Zambia & $12^{\circ} 44^{\prime}$ & $24^{\circ} 20^{\prime}$ & EF043483-EF043484 \\
\hline micklemi & 2 & Watopa, South of Kabompo River, Zambia & $14^{\circ} 00^{\prime}$ & $23^{\circ} 47^{\prime}$ & EF043485-EF043486 \\
\hline micklemi & 1 & Namwala N, Zambia & $15^{\circ} 40^{\prime}$ & $26^{\circ} 25^{\prime}$ & EF043487 \\
\hline micklemi & 1 & Namwala $S$, Zambia & NA & NA & EF043488 \\
\hline micklemi & 1 & Munali1, Zambia & $15^{\circ} 57^{\prime}$ & $28^{\circ} 07^{\prime}$ & EF043489 \\
\hline micklemi & 1 & Munali2, Zambia & $15^{\circ} 58^{\prime}$ & $28^{\circ} 08^{\prime}$ & EF043490 \\
\hline micklemi & 1 & Moono, Zambia & $15^{\circ} 08^{\prime}$ & $26^{\circ} 57^{\prime}$ & EF043491 \\
\hline micklemi & 1 & Kaindu, Zambia & $14^{\circ} 29^{\prime}$ & $26^{\circ} 54^{\prime}$ & EF043492 \\
\hline micklemi & 1 & Lusaka, Zambia* & $15^{\circ} 19^{\prime}$ & $28^{\circ} 27^{\prime}$ & AF012233 \\
\hline micklemi & 2 & Kataba, Zambia* & $15^{\circ} 23^{\prime}$ & $23^{\circ} 23^{\prime}$ & EF043493-EF043494 \\
\hline micklemi & 1 & Senanga, Zambia & $15^{\circ} 58^{\prime}$ & $23^{\circ} 20^{\prime}$ & EF043495 \\
\hline micklemi & 1 & Luampa, Zambia & $22^{\circ} 46^{\prime}$ & $24^{\circ} 56^{\prime}$ & EF043496 \\
\hline micklemi & 1 & Mazabuka, Zambia & $16^{\circ} 12^{\prime}$ & $27^{\circ} 25^{\prime}$ & EF043497 \\
\hline micklemi & 1 & Monze, Zambia & $16^{\circ} 04^{\prime}$ & $27^{\circ} 32^{\prime}$ & EF043498 \\
\hline micklemi & 1 & Lochinvar, Zambia* & $16^{\circ} 06^{\prime}$ & $27^{\circ} 18^{\prime}$ & EF043499 \\
\hline micklemi & 2 & Dongo, Zambia & $16^{\circ} 38^{\prime}$ & $26^{\circ} 27^{\prime}$ & EF043500-EF043501 \\
\hline micklemi & 1 & Kalomo, Zambia & $16^{\circ} 58^{\prime}$ & $26^{\circ} 36^{\prime}$ & AF012234 \\
\hline micklemi & 2 & Kavumba, Zambia & $17^{\circ} 35^{\prime}$ & $25^{\circ} 21^{\prime}$ & EF043502-EF043503 \\
\hline micklemi & 2 & Kalamba near Sekute, Zambia & $17^{\circ} 38^{\prime}$ & $25^{\circ} 41^{\prime}$ & EF043504-EF043505 \\
\hline micklemi & 1 & Sekute, Zambia & $17^{\circ} 38^{\prime}$ & $25^{\circ} 41^{\prime}$ & EF043506 \\
\hline micklemi & 1 & Libala near Sekute, Zambia & $17^{\circ} 38^{\prime}$ & $25^{\circ} 41^{\prime}$ & EF043507 \\
\hline micklemi & 1 & Kabala near Sekute, Zambia & $17^{\circ} 38^{\prime}$ & $25^{\circ} 41^{\prime}$ & EF043508 \\
\hline micklemi & 1 & Ndrevu, Zambia & $17^{\circ} 38^{\prime}$ & $25^{\circ} 41^{\prime}$ & EF043509 \\
\hline micklemi & 1 & Livingstone, Zambia & $17^{\circ} 54^{\prime}$ & $25^{\circ} 53^{\prime}$ & EF043510 \\
\hline micklemi & 1 & Itezhi-Itezhi, Zambia* & $15^{\circ} 51^{\prime}$ & $26^{\circ} 03^{\prime}$ & EF043516 \\
\hline micklemi & 3 & Mikata, Zambia & NA & NA & EF043511-EF043512 \\
\hline micklemi & 3 & Kajunika lila, Zambia & NA & NA & EF043513-EF043515 \\
\hline C. nimrodi & 1 & Hillside, Bulawayo, Zimbabwe & $20^{\circ} 09^{\prime}$ & $28^{\circ} 38^{\prime}$ & AF012237 \\
\hline C. hottentotus & 1 & Steinkopf, South Africa & $29^{\circ} 17^{\prime}$ & $17^{\circ} 45^{\prime}$ & $\begin{array}{l}\text { AF } 12240 \\
\text { (continued on next page) }\end{array}$ \\
\hline
\end{tabular}


Table 1 (continued)

\begin{tabular}{|c|c|c|c|c|c|}
\hline Clade & $\mathrm{N}$ & Location and country & Lat $(\mathrm{S})$ & Lon $(\mathrm{E})$ & GenBank No. \\
\hline C. pretoriae & 1 & Pretoria, South Africa & $25^{\circ} 47^{\prime}$ & $28^{\circ} 13^{\prime}$ & AF12235 \\
\hline C. mahali & 1 & Patryshoek, Pretoria, South Africa & $25^{\circ} 40^{\prime}$ & $28^{\circ} 02^{\prime}$ & AY524870 \\
\hline C. natalensis & 1 & Kokstad, South Africa & $31^{\circ} 32^{\prime}$ & $29^{\circ} 38^{\prime}$ & AF12236 \\
\hline B. suillus & 1 & Rondawel, South Africa & $30^{\circ} 47^{\prime}$ & $17^{\circ} 53^{\prime}$ & AY425913 \\
\hline
\end{tabular}

Genomic DNA was isolated by proteinase-K digestion followed by extraction over Qiagen DNAEasy spin columns(Hilden, Germany) according to the manufacturers' instructions. PCR amplification of the complete cyt $b$ (1140 base pairs) was carried out using primers (L14723 and H15915) and reaction conditionsdescribedpreviouslyforAfricanmole-rats(Faulkes etal., 1997).Sequencingwascarriedoutinbothdirectionsusing the PCR primers to obtain partially overlapping strands. Sequencing reactions were performed on an ABI 377 automatedsequencerusingBigDyeTerminatorv3.1 chemistry (Applied Biosystems, Foster City, CA). All new sequences (including voucher references) have been deposited in NCBI with Accession Nos. EF043451-EF043516(Table 1).

\subsection{Sequence and phylogenetic analyses}

Previously published cytochrome b sequences from Fukomys specimens from the Zambezian area (Faulkes et al., 2004) were obtained from NCBI and included in the analyses (although many are partial cyt $b$ sequences; Table 1). The compiled sequences were subsequently aligned using ClustalW (Thompson et al., 1994) in MEGA v3.0 (Kumar et al., 2004). Based on previous studies (Faulkes et al., 2004; Ingram et al., 2004), other bathyergids, five Cryptomys species and Bathyergus suillus (Table 1) (Faulkes et al., 2004) were included as outgroup taxa. Calculation of genetic distances and both maximum parsimony (MP) analysis and two probabilistic approaches, maximum likelihood (ML) and Bayesian analyses, were performed on the complete dataset. Both for reasons of clarity and to limit computing time, we used a subset of representative haplotypes in the final analyses. Datasets were examined for substitution saturation (transversions and transitions separately) plotting matrices of patristic against adjusted character distances calculated by PAUP* v4.0b11. For $\mathrm{ML}$ and Bayesian analysis we included $C$. nimrodi as the only outgroup taxon. Prior to ML and Bayesian analyses Akaike information criterion (AIC) tests of different models of evolution were performed with Modeltest v3.07 (Posada and Crandall, 1998). MP and ML analyses were performed using PAUP* v4.0b11 (Swofford, 2002). For the MP analyses we used the heuristic search option with characters having an equal weight. In a second round of MP analyses characters were then weighted a posteriori (Farris, 1969) according to their rescaled consistency index (RC; Farris, 1989). Under these MP criteria bootstrap proportions (BP) were calculated, using 1000 pseudoreplicates, random addition of taxa and TBR branch swapping with the steepest descent option not in effect. For ML analyses we employed the heuristic search option with TBR branch swapping, where starting trees were obtained via random stepwise addition. Robustness of the ML tree was determined in a bootstrap analysis using the stepwise addition option and the heuristic search option with 500 pseudoreplicates (Felsenstein, 1985). Bayesian posterior probabilities (PP) were estimated using MrBayes v3.01 (Ronquist and Huelsenbeck, 2003). The analyses were initiated with random starting trees and were run for $1 \times 10^{6}$ generations, sampling every $100^{\text {th }}$ generation. Likelihood values were checked graphically to see if stationarity had been reached. Four separate independent searches were run, each consisting of three heated chains and one cold chain. The burn-in value was set at 500. Thus the first 500 trees $(50,000$ generations) were discarded in the approximation of posterior probabilities. The trees of the various runs were combined, producing a $50 \%$ majority rule consensus tree. All trees were visualised with Treeview 1.6.6 (Page, 1996).

\subsection{Estimation of divergence time}

Phylogenetic dating was applied to genetic distances inferred from a ML tree. A likelihood ratio test (Felsenstein, 1981), as well as Tajima's relative rate tests (RRT; Tajima, 1993), indicated that the cytochrome b dataset departs slightly from true clocklike evolution. To identify significant differences in substitution rate between lineages we used the two-cluster test of the LINTRE package (Takezaki et al., 1995) Substitution rate varies among lineages (see below). Therefore, we applied two different methods which relax the stringency of the molecular clock assumption to estimate time of divergence: (1) a semiparametric rate smoothing method, using the penalised likelihood smoothing (PLS) approach; and (2) a non-parametric rate smoothing (NPRS) method. Both were implemented in R8s version 1.7 (Sanderson, 1997, 2003). For the penalised likelihood smoothing approach, an optimal (=lowest) smoothing value was determined by a cross-validation procedure (Sanderson, 2004). Following the recommendations of the author of that application, we trimmed the original ML phylogeny, retaining only unique haplotypes $(N=29)$. There are only a few reliable calibration points to estimate divergence time in the derived lineages of the Bathyergidae (for a review of fossil data, see Faulkes et al., 2004). Following Ingram et al. (2004), who estimated the divergence of Cryptomys and Fukomys between approximately 10 and 11 Mya, using NPRS on a combined data set of the mitochrondrial 12s ribosomal 
RNA and the nuclear transthyretin (TTR) gene, we used 10 and 11 Mya as calibration points in our analyses.

\section{Results}

\subsection{Relationships between major clades}

Maximum parsimony analysis recovered three trees of equal length (1068 steps). Out of 1140 sites which were examined, 695 were constant, 320 were parsimony informative and 125 were uninformative. MP analysis after reweighting characters with their rescaled consistency index (RI) resulted in 256 characters not retaining a character weight of one and recovering three trees (consistency index $=0.495$ retention index $=0.799$ rescaled consistency index $=0.396$ homoplasy index $=0.505$ ). Fig. 2 shows the consensus tree based on the reweighted character set. Initial analysis (not shown) demonstrated that the inclusion of previously published sequences did not affect the overall topology compared with previously published phylogenies (Ingram et al., 2004; Faulkes et al., 2004). The major phylogroups that were also recovered in previous studies (op. cit.) formed well-supported monophyletic groups: $F$. bocageilmechowii clade, $F$. whytei clade, $F$. darlingi clade, $F$. damarensis clade and F. micklemi clade. According to the AIC tests of model evolution, the TIM model corrected for invariable sites and among-site rate variation using the discrete gamma distribution was found to best fit the data. A manual selection procedure (Swofford and Sullivan, 2003) resulted in GTR $+\mathrm{I}+\Gamma$ as the best choice. Both models produced $\mathrm{ML}$ trees with the same topology. The inferred ML tree (Fig. 3) differs slightly from the MP tree, the ML tree being two steps longer than the single most parsimonious tree $(\mathrm{TL}=1070$ vs. 1068 , respectively). The only difference between the MP and ML trees concerns the placement of $F$. bocagei, while it forms a monophyletic group with the $F$. mechowii clade in the MP tree, it is basal to all other major clades in the ML tree. Note that in all analyses the enigmatic $F$. cf. whytei haplotype from Mzuzu forms a divergent, basal lineage to the $F$. whytei clade $(\mathrm{BP}=72$, $\mathrm{PP}=0.97)$. The Bayesian analysis yields the same topology as the ML tree and generated high posterior probabilities for all the major phylogroups (Fig. 3).

\subsection{Relationships within major phylogroups}

In comparison with previous studies, the clades for which the sampling range was extended provide a detailed phylogeographic picture for the various groups. In each case similar topologies were recovered in all analyses.

\subsubsection{Fukomys mechowii clade (Fig. 4)}

In all analyses two reciprocal monophyletic subclades were recovered. MP analysis, however, gave strong support for both subclades as opposed to both probabilistic analy- ses, which provide only weak support for the monophyly of the Salujinga/Kinshasa subclade $(\mathrm{BP}=66 ; \mathrm{PP}=0.72)$. The other subclade consists of all $F$. mechowii haplotypes, including the haplotype from near the type locality of Georychus mellandi (Thomas, 1906).

\subsubsection{Fukomys whytei clade (Fig. 5)}

Six subclades can be distinguished within the whytei clade (making abstraction of the $F$. cf. whytei haplotype from Mzuzu, Malawi (MZU)-see above). A first divergence contains the Western Bangweulu subclade (WBA), which forms a strongly supported monophyletic group with the $F$. amatus subclade. Both subclades are strongly supported in all analyses and are characterised by long branches leading to the subclades relative to branch lengths observed within the subclades. The monophyly of a second divergent lineage is weakly supported $(\mathrm{BP}=67$; $\mathrm{BP}=0.76)$. It comprises, on the one hand, a well supported clade containing the Kasama (KAS), Eastern Bangweulu (EBA) and Lufubu (LUF) subclades. On the other hand, there is a basal clade with the topotypical $F$. whytei haplotype (Karonga) and the Mbala haplotype. Results from the initial analyses (not shown) indicate that this clade also contains the Tanzanian haplotype (Suma; excluded from later analyses because the obtained sequence was shorter).

\subsubsection{Fukomys damarensis clade (Fig. 3)}

The divergence pattern within the group of the eusocial Damaraland mole-rat is shallow. In all analyses the two Southwest Zambian haplotypes cluster with the geographically proximate haplotypes. The Simungoma haplotype from North of the Zambezi River is sister to this subclade. This is the first time a member of the $F$. damarensis clade has been discovered north of the Zambezi River. Interestingly, $F$. damarensis are morphologically very similar to the mole-rats of the F. micklemi clade, to which they are closely related.

\subsubsection{Fukomys micklemi clade (Fig. 6)}

This sister group to the $F$. damarensis clade is also characterised by relatively short branches. In all analyses we recovered a subtree with three main lineages, although their interrelationships remain unresolved: 1 . the Watopa (WAT) subclade, which is sister to all other taxa in the clade; 2 . the Chinyingi (CHI) subclade from West of the Zambezi River; and 3. a major radiation that includes all chromosomal races from South Central Zambia. In turn, this South Central Zambian subclade contains three monophyletic lineages including, respectively, topotypical $F$. kafuensis (Itezhi-Itezhi), F. anselli (Lusaka) and. F. micklemi (Kataba). Although the monophyly of the Kataba and Itezhi-Itezhi groups is well supported, the interrelationships among the members of these karyotypically hyper-diverse groups remain partly unresolved. The bootstrap support for the Lusaka group, containing all haplotypes of animals with $2 n=68$, is weak $(\mathrm{BP}=63 ; \mathrm{PP}=0.64)$. In the $\mathrm{MP}$ analysis the 


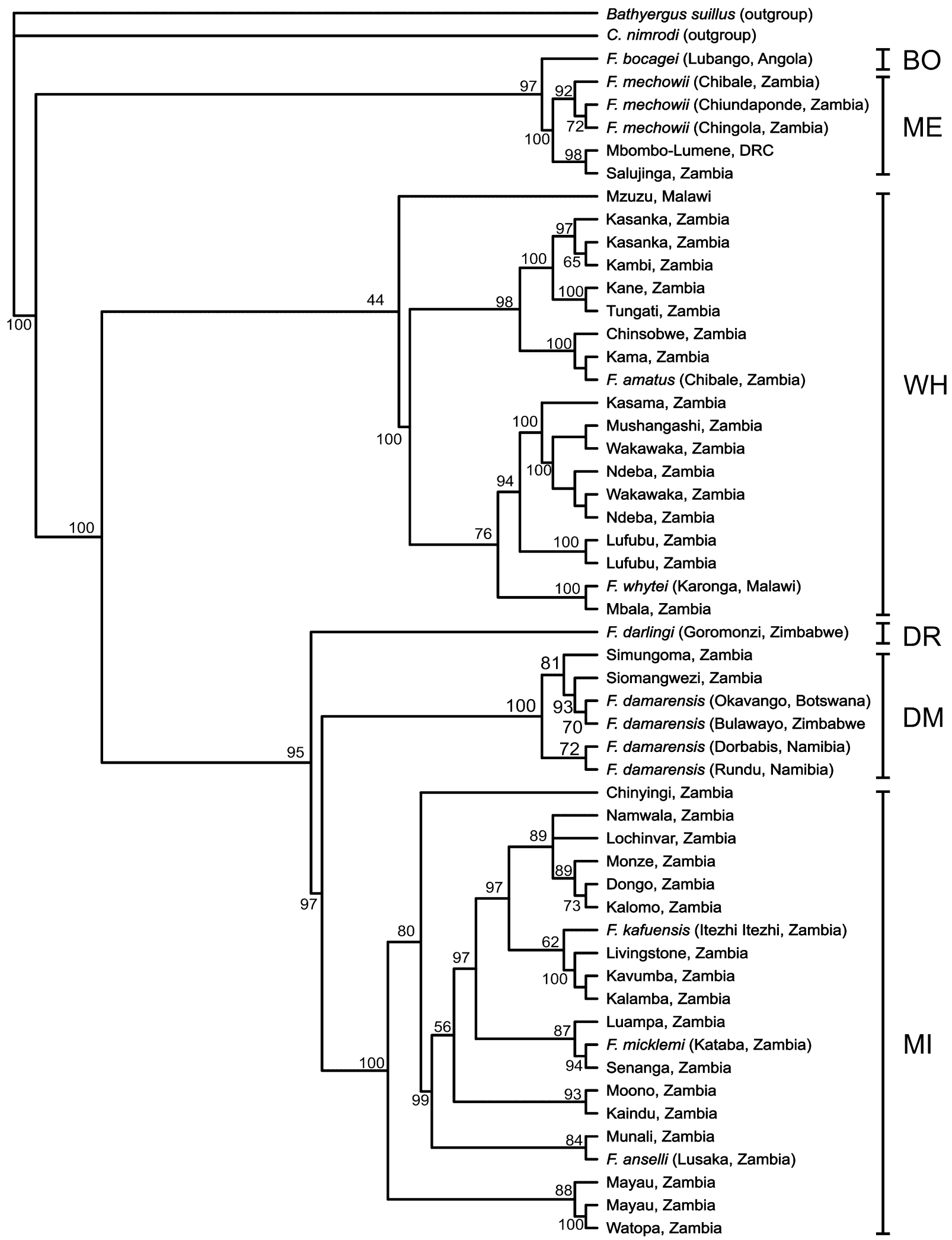

Fig. 2. Maximum parsimony estimate of the Zambezian Fukomys phylogeny based on cytochrome b gene sequences: $50 \%$ majority rule consensus tree using the heuristic search option (tree length $=1068$, consistency index $=0.495$, rescaled consistency index $=0.396$ ). For all branches values above the branches refer to bootstrap proportions after weighting sites with their rescaled consistency index. Major clades: BO, F. bocagei clade; ME, F. mechowii clade; WH, F. whytei clade; DR, F. darlingi clade; DM, F. damarensis clade; MI, F. micklemi clade. 


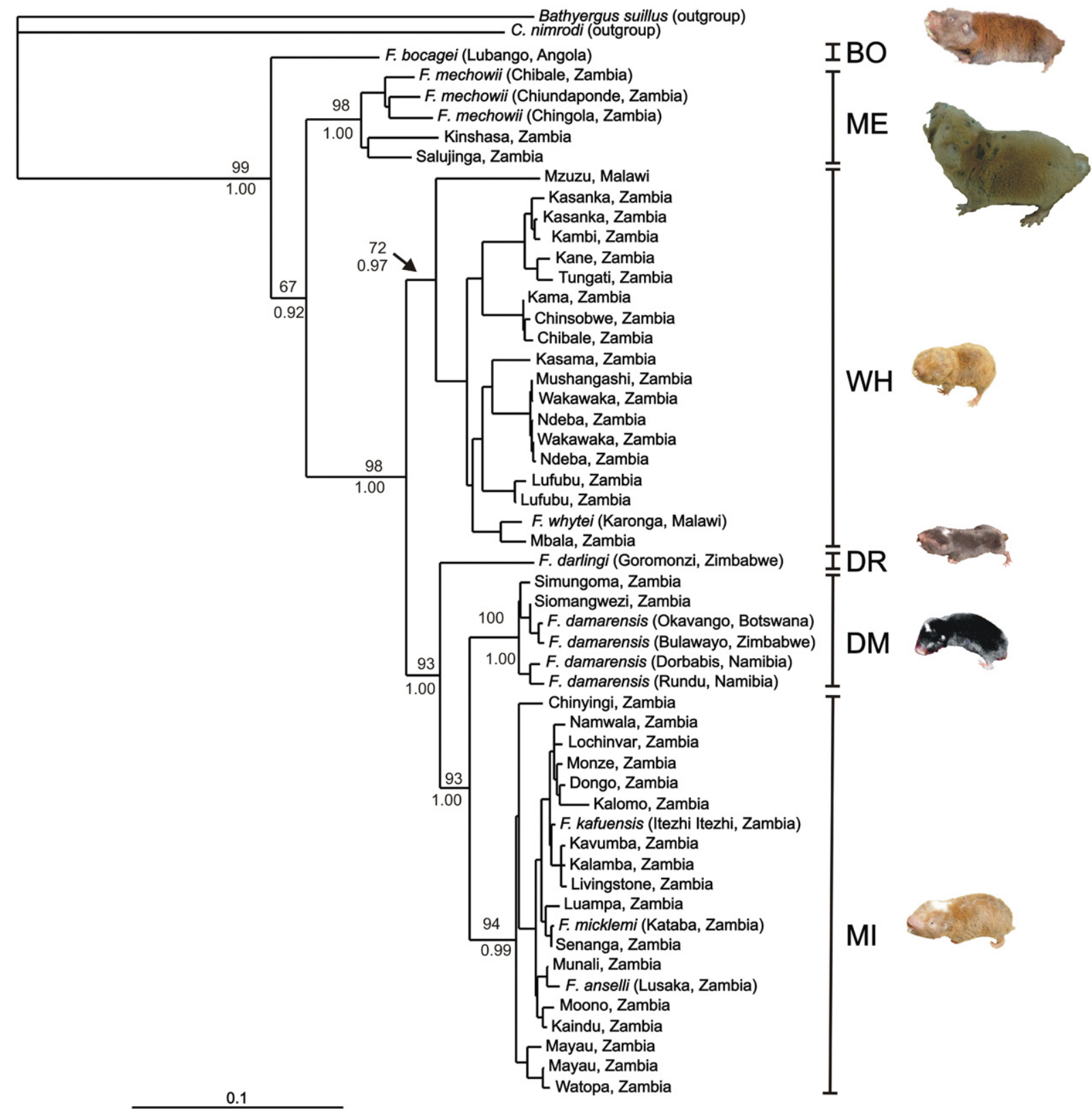

Fig. 3. Maximum likelihood estimate of the Fukomys phylogeny based on cytochrome b gene sequences. The ML analysis using a TIM $+\mathrm{I}+\Gamma$ model of sequence evolution $(R=1.000030 .35221 .53041 .5304$ 17.4605; Pinvar $=0.5192$ gamma shape parameter $=2.1328)$ generated a tree with $-\ln \mathrm{L}=7774.03$ and tree length $=1070$. Values above the branches indicate ML bootstrap proportions (1000 replicates), while values under the branches refer Bayesian posterior probabilities. The scale bar represents the number of substitutions per site. Major clades: $\mathrm{BO}, F$. bocagei; ME, F. mechowii clade; WH, F. whytei clade; DR, F. darlingi clade; DM, F. damarensis clade; MI, F. micklemi clade.

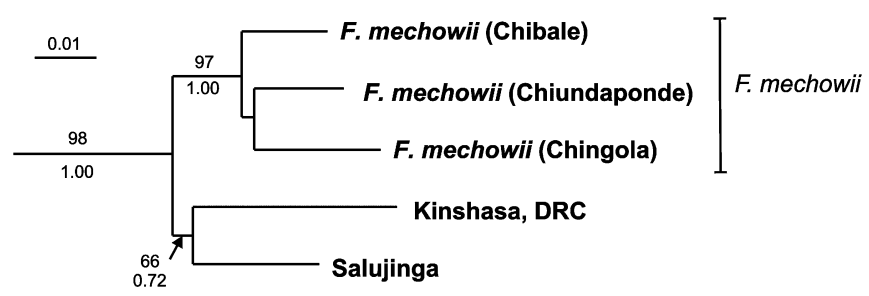

Fig. 4. ML subtree of F. mechowii clade (cf. Fig. 3).

haplotypes of the Lusaka group are paraphyletic (Moono and Kaindu haplotypes vs. Munali and Lusaka haplotypes).

\subsection{Intra- and interspecific sequence differences}

Both uncorrected and TIM $+\mathrm{I}+\Gamma$ corrected distances are listed in Table 2. Average corrected (TIM $+\mathrm{I}+\Gamma$ ) pairwise sequence differences between outgroup and ingroup taxa ranged from 21.5 to $28.4 \%$ (mean $=26.3 \%)$. The average corrected pairwise distances among and within the ingroup taxa (subclades) were $9.6 \%$ (Range: $1.7-15.5$ ) and $1.0 \%$ (Range: 0.3-2.5), respectively. The highest distances are found between the $F$. bocagei clade (basal lineage in the ML phylogeny) and the other clades (range: $12.8-15.5 \%$ ) 


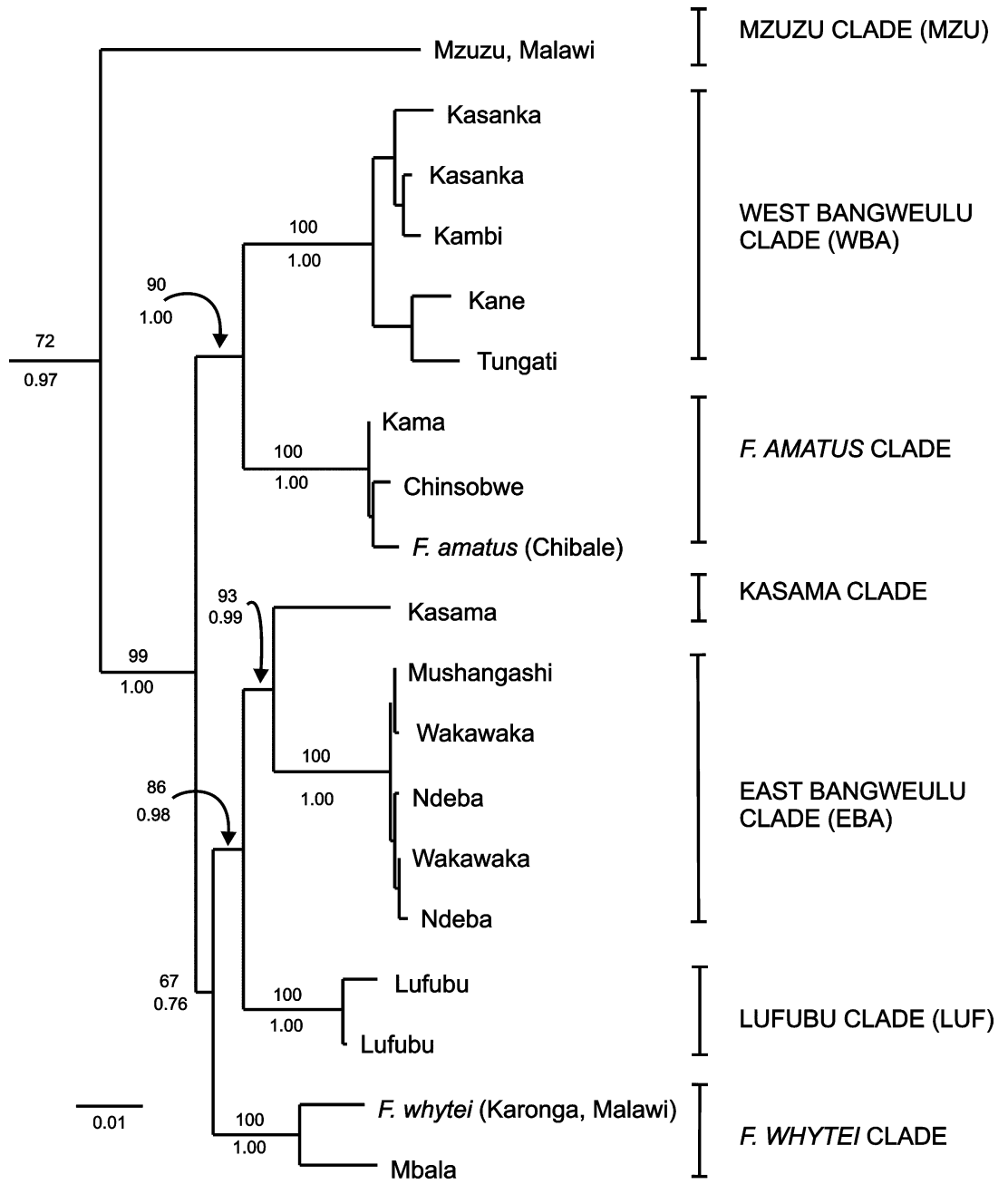

Fig. 5. ML subtree of F. whytei clade (cf. Fig. 3).

with a maximum between the Mzuzu and $F$. bocagei haplotypes. The lowest distances are observed among the subclades of the F. micklemi clade (Range: 1.7-3.6), with particularly low values between the $F$. anselli subclade and $F$. micklemi subclades $(1.7 \%)$ and between the $F$. micklemi and $F$. kafuensis subclades (1.8\%). The highest $\mathrm{TIM}+\mathrm{I}+\Gamma$ corrected distances within the $\mathrm{F}$. micklemi clade were found between the Chinyingi and Watopa subclades on the one hand and all remaining clades on the other hand (respective ranges: $2.5-4.1$ and 2.8-4.7). A remarkably low level of genetic divergence is found within the chromosomally hyper-diverse $F$. micklemi subclade. The average $\mathrm{TIM}+\mathrm{I}+\Gamma$ corrected distance within this phylogroup is $0.6 \%$, with an interhaplotype range of 0.1 to $1.6 \%$, excluding the Kalomo haplotype, which appears to be considerably more dissimilar from the other haplotypes (range 1.6-3.0\%). Within the F. whytei clade, the Mzuzu haplotype is an outlier with $\mathrm{TIM}+\mathrm{I}+\Gamma$ corrected distances that differ on average $8.4 \%$ from all other haplotypes in this subclade. The two Zambian haplotypes show genetic divergence levels that are similarly low as in other haplotypes of this clade. Among major clades average corrected $\mathrm{TIM}+\mathrm{I}+\Gamma$ distances correlate well with geographic dis- tance, while within there is no apparent trend in any of the major clades.

\subsection{Estimates of divergence times}

For this analysis we used a subset of the data. Graphical saturation analysis indicates a linear relationship up to $20 \%$ p-distance, while beyond that level slight substitution saturation occurred in transition substitutions only. These values correspond to comparisons with outgroups. Therefore, both substitution types were used to calculate estimates of divergence times (Table 3 and Fig. 7). The value of the PL models' optimal smoothing value was set to 1 , illustrating a poor fit to a molecular clock and allowing for considerable rate heterogeneity across branches. Significant departures from rate constancy were observed in comparisons between the major lineages (Table 4) Using the calibration of 10 11 Mya for the divergence of Fukomys and Cryptomys we were able to estimate key cladogenetic events. The obtained results suggest that all major clades radiated during the Pleistocene. A northern Zambezian lineage (containing the $F$. whytei clade) evolved into separate subclades from the Late Pliocene on (Fig. 7, node E). In contrast, two 


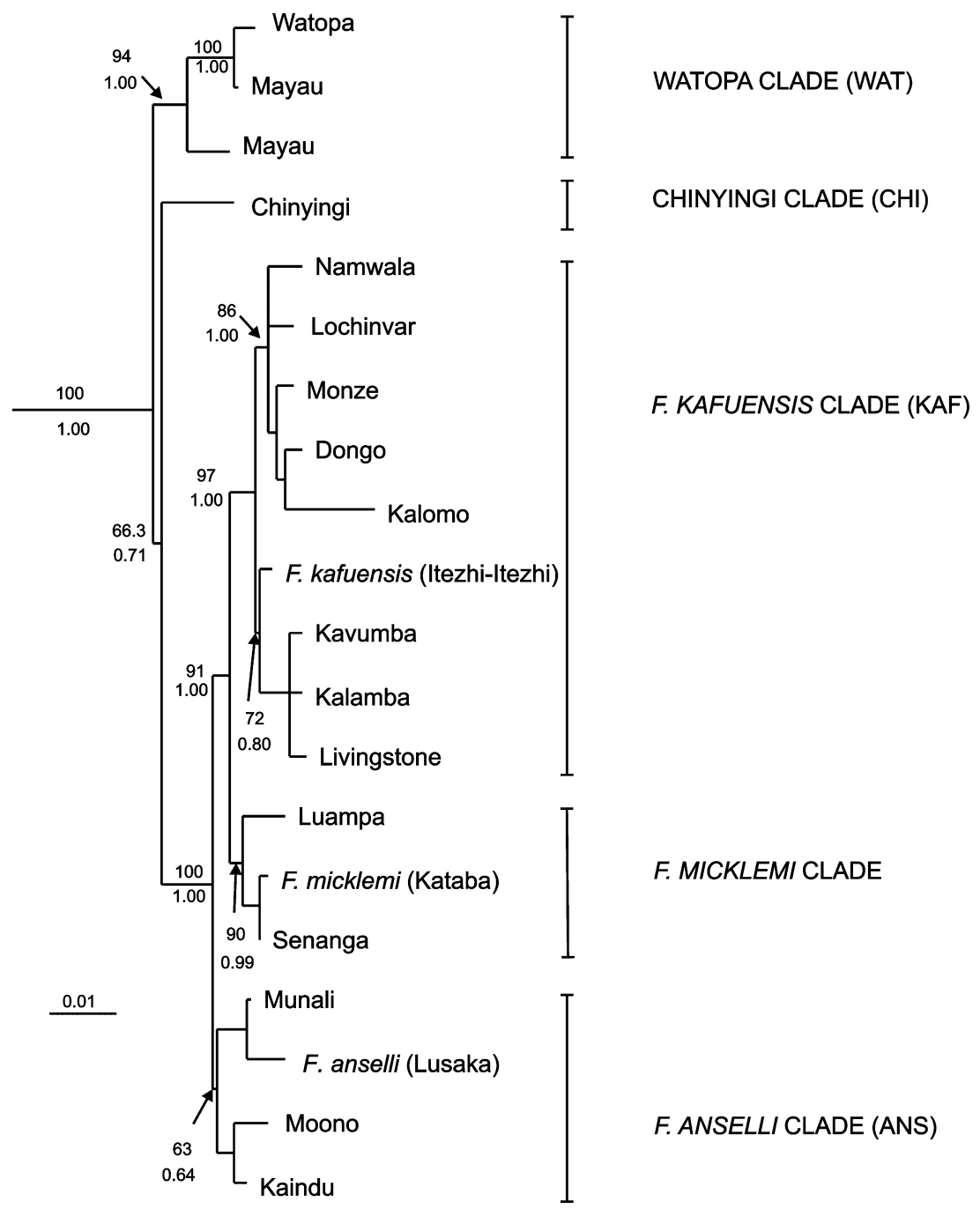

Fig. 6. ML subtree of F. micklemi clade (cf. Fig. 3).

southern Zambezian lineages-the $F$. damarensis clade and the $F$. micklemi clade - constitute more recent radiations dating back to the middle Pleistocene. The chromosomal radiation within the $F$. micklemi subclade is dated at 0.56-1.2 Mya (Fig. 7, nodes L and M).

\section{Discussion}

\subsection{Phylogenetic relationships}

Within Zambezian Fukomys our cytochrome b analyses recovered the same overall topology as in previous molecular sequence studies (Ingram et al., 2004; Faulkes et al., 2004). At the base of the Zambezian Fukomys trees the exact position of the F. bocagei clade remains unclear. To address this problem, denser sampling in the presumably exclusively Angolan distribution range of $F$. bocagei clade will be necessary. Earlier studies showed that small molerats (i.e. representatives from the $F$. whytei, $F$. darlingi, $F$. damarensis and $F$. micklemi clades), do not constitute a monophyletic assemblage of haplotypes (op. cit.). For example, the Salujinga haplotypes cluster within the $F$. mechowii clade, implying that the representatives of this small race are closely related to the giant mole-rats $(F$. mechowii clade), a finding that is supported by the similarity of their karyotypes (Van Daele et al., 2004). This chromosomal race is congruent in external morphology with the robust mole-rats from the geographically close Watopa phylogroup (a group within the derived $F$. micklemi clade). In view of the poor support in the ML for the monophyly of the Salujinga and Kinshasa haplotypes, the latter presumably forms a separate divergent lineage. The $F$. mechowii clade encompasses robust to giant forms, which are uniformly brown in colour (Fig. 3). The monophyly of the whytei clade is not well supported. In spite of our extended sampling in the Zambian distribution range of the $F$. whytei clade, the affinities of the Mzuzu haplotype remain unclear (cf. low bootstrap values), though it appears to have a basal position in relation to the different F. whytei subclades. All these subclades form well supported monophyletic groups that are genetically well differentiated (3.1-5.8\%). This finding may be a result of 
Table 2

Mean cytochrome $\mathrm{b}$ distances between sequences $(\%)^{\mathrm{a}}$

\begin{tabular}{|c|c|c|c|c|c|c|c|c|c|c|c|c|c|c|c|c|c|c|c|c|}
\hline \multirow{2}{*}{$\begin{array}{l}\text { Clade } \\
\text { Subclade }\end{array}$} & \multicolumn{3}{|c|}{ MECHOWII clade } & \multirow{2}{*}{$\begin{array}{l}\text { BOC } \\
\text { F. boc }\end{array}$} & \multicolumn{7}{|c|}{ WHYTEI clade } & \multirow{2}{*}{$\begin{array}{l}\text { DAM } \\
\text { F. dam }\end{array}$} & \multirow{2}{*}{$\begin{array}{l}\text { DAR } \\
\text { F. dar }\end{array}$} & \multicolumn{5}{|c|}{ MICKLEMI clade } & \multirow[t]{2}{*}{ CRY } & \multirow[t]{2}{*}{ BAT } \\
\hline & F. mec & KIN & SAL & & WBA & F. ama & EBA & KAS & LUF & F. why & $\mathrm{MZU}$ & & & $\mathrm{CHI}$ & WAT & KAF & ANS & F. mick & & \\
\hline $\mathrm{n} / \mathrm{N}$ & $4 / 4$ & $1 / 1$ & $2 / 3$ & $1 / 1$ & $6 / 9$ & $3 / 4$ & $5 / 5$ & $1 / 1$ & $2 / 2$ & $3 / 5$ & $1 / 1$ & $16 / 17$ & $1 / 1$ & $1 / 1$ & $4 / 4$ & $18 / 23$ & $4 / 5$ & $4 / 4$ & $5 / 5$ & $1 / 1$ \\
\hline F. mec & 2.4 & 5.3 & 4.6 & 10.5 & 11.5 & 11.1 & 11.3 & 10.9 & 10.9 & 12.3 & 12.4 & 13.2 & 11.8 & 13.0 & 13.0 & 13.3 & 13.4 & 13.2 & 28.4 & 25.0 \\
\hline KIN & 4.9 & $N A$ & 4.8 & 12.4 & 12.4 & 11.6 & 11.8 & 12.3 & 12.5 & 13.4 & 12.7 & 14.5 & 13.0 & 13.7 & 13.8 & 14.2 & 14.6 & 14.6 & 27.0 & 24.8 \\
\hline SAL & 4.3 & 4.5 & $<0.1$ & 10.8 & 11.5 & 12.4 & 11.7 & 11.7 & 11.8 & 12.9 & 12.3 & 13.5 & 11.1 & 11.8 & 13.0 & 12.9 & 13.0 & 12.5 & 28.1 & 26.4 \\
\hline F. boc & 9.0 & 10.4 & 9.2 & $N A$ & 13.1 & 12.8 & 13.6 & 12.8 & 12.9 & 12.8 & 15.5 & 13.2 & 15.1 & 13.5 & 13.2 & 14.5 & 13.4 & 13.8 & 24.5 & 24.7 \\
\hline WBA & 9.6 & 10.3 & 9.6 & 10.9 & 1.4 & 5.0 & 5.1 & 4.6 & 4.9 & 5.8 & 8.0 & 10.1 & 8.9 & 9.5 & 9.7 & 9.7 & 9.5 & 9.4 & 27.2 & 24.2 \\
\hline F. ama & 9.4 & 9.7 & 10.2 & 10.7 & 4.6 & 0.3 & 5.6 & 4.3 & 5.2 & 5.5 & 8.9 & 9.6 & 9.5 & 9.2 & 9.0 & 10.5 & 9.9 & 10.0 & 25.6 & 23.7 \\
\hline EBA & 9.4 & 9.8 & 9.8 & 11.2 & 4.7 & 5.0 & 0.3 & 3.1 & 3.8 & 5.0 & 9.0 & 9.8 & 9.2 & 9.8 & 9.8 & 9.8 & 10.1 & 10.1 & 26.1 & 22.4 \\
\hline KAS & 9.2 & 10.2 & 9.8 & 10.7 & 4.2 & 4.0 & 3.0 & $N A$ & 3.4 & 4.5 & 8.5 & 8.8 & 8.8 & 8.7 & 9.1 & 9.8 & 9.4 & 9.3 & 24.8 & 21.6 \\
\hline LUF & 9.3 & 10.4 & 9.9 & 10.8 & 4.5 & 4.7 & 3.5 & 3.1 & 0.7 & 4.4 & 7.2 & 8.7 & 8.3 & 9.5 & 9.6 & 10.1 & 10.0 & 9.8 & 25.2 & 21.5 \\
\hline F. why & 10.2 & 11.0 & 10.6 & 10.7 & 5.3 & 5.0 & 4.6 & 4.2 & 4.1 & 1.5 & 9.1 & 8.7 & 8.9 & 9.3 & 9.5 & 10.4 & 9.8 & 9.8 & 26.0 & 22.4 \\
\hline MZU & 10.2 & 10.5 & 10.1 & 12.4 & 7.0 & 7.7 & 7.7 & 7.4 & 6.4 & 7.8 & $N A$ & 9.1 & 9.3 & 10.1 & 10.1 & 10.1 & 10.4 & 10.0 & 25.8 & 23.8 \\
\hline F. dam & 10.8 & 11.7 & 11.0 & 10.9 & 8.6 & 8.3 & 8.5 & 7.7 & 7.6 & 7.6 & 7.9 & 1.3 & 8.0 & 6.6 & 6.5 & 7.0 & 6.4 & 6.8 & 24.7 & 22.3 \\
\hline F. dar & 9.9 & 10.7 & 9.4 & 12.2 & 7.7 & 8.2 & 8.0 & 7.7 & 7.4 & 7.8 & 8.1 & 7.1 & $N A$ & 7.9 & 8.3 & 7.9 & 7.9 & 8.0 & 27.1 & 22.9 \\
\hline CHI & 10.5 & 11.1 & 9.8 & 11.1 & 8.1 & 7.9 & 8.4 & 7.6 & 8.2 & 8.1 & 8.6 & 5.9 & 7.0 & $N A$ & 2.8 & 3.6 & 3.0 & 3.0 & 25.9 & 23.9 \\
\hline WAT & 10.6 & 11.1 & 10.5 & 10.9 & 8.3 & 7.8 & 8.4 & 7.9 & 8.2 & 8.2 & 8.6 & 5.9 & 7.3 & 2.6 & 0.7 & 3.7 & 3.1 & 3.1 & 26.4 & 23.7 \\
\hline KAF & 10.8 & 11.5 & 10.5 & 11.7 & 8.4 & 9.0 & 8.4 & 8.4 & 8.7 & 8.9 & 8.6 & 6.3 & 7.0 & 3.4 & 3.5 & 1.0 & 2.2 & 1.8 & 26.2 & 23.6 \\
\hline ANS & 10.9 & 11.7 & 10.6 & 11.1 & 8.1 & 8.5 & 8.7 & 8.1 & 8.6 & 8.4 & 8.8 & 5.8 & 7.0 & 2.9 & 3.0 & 2.1 & 1.1 & 1.7 & 26.7 & 23.5 \\
\hline F. mick & 10.7 & 11.7 & 10.3 & 11.3 & 8.1 & 8.6 & 8.7 & 8.0 & 8.4 & 8.4 & 8.5 & 6.1 & 7.1 & 2.8 & 3.0 & 1.8 & 1.6 & 0.6 & 27.0 & 23.8 \\
\hline CRY & 19.0 & 18.5 & 19.0 & 17.6 & 18.6 & 17.8 & 18.2 & 17.6 & 17.8 & 18.1 & 18.1 & 17.4 & 18.4 & 17.9 & 18.2 & 18.0 & 18.2 & 18.3 & 9.7 & 24.6 \\
\hline BAT & 17.6 & 17.6 & 18.2 & 17.6 & 17.4 & 17.3 & 16.7 & 16.1 & 16.1 & 16.5 & 17.2 & 16.5 & 16.9 & 17.1 & 17.1 & 17.0 & 16.9 & 17.1 & 17.4 & $N A$ \\
\hline
\end{tabular}

${ }^{\mathrm{a}}$ Below diagonal TIM $+\mathrm{I}+\Gamma$ corrected distances, above diagonal uncorrected $\mathrm{p}$ distances, along diagonal within clade uncorrected $\mathrm{p}$ distances. The following taxa are included: $\mathrm{F}$. mec, $F$. mechowii; KIN, Kinshasa; BOC/F. boc, F. bocagei; WBA, western Bangweulu group; F. ama, F. amatus; EBA, eastern Bangweulu group; KAS, Kasama group; LUF, Lufubu group; F. why, F. whytei; MZU, Mzuzu group; DAR/F.dar, $F$. darlingi; DAM/F. dam, $F$. damarensis; CHI, Chinyingi group; WAT, Watopa group; KAF, containing topotypical $F$. kafuensis clade (2 $n=42-58$ ); ANS, containing topotypical Fukomys anselli $(2 n=68)$; F. mick, F. micklemi $(2 n=60)$; CRY, Cryptomys species.; BAT, Bathyergus suillus. 
Table 3

Estimated dates of divergence (Mya) for nodes in Fig. 7 using NPRS and PLS $^{\mathrm{a}}$

\begin{tabular}{lll}
\hline NODE & PLS 10\&11 & NPRS 10\&11 \\
\hline CRY & $10-11$ & $10-11$ \\
$\mathrm{~A}$ & $3.8-4.18$ & $5.45-6$ \\
$\mathrm{~B}$ & $1.41-1.55$ & $2.98-3.28$ \\
$\mathrm{C}$ & $3.33-3.66$ & $4.88-5.37$ \\
$\mathrm{D}$ & $2.15-2.37$ & $3.19-3.51$ \\
$\mathrm{E}$ & $1.84-2.02$ & $2.75-3.02$ \\
$\mathrm{~F}$ & $1.28-1.41$ & $1.92-2.11$ \\
$\mathrm{G}$ & $1.01-1.11$ & $1.47-1.61$ \\
$\mathrm{H}$ & $1.11-1.22$ & $1.7-1.88$ \\
$\mathrm{I}$ & $1.7-1.87$ & $2.58-2.84$ \\
$\mathrm{~J}$ & $1.3-1.43$ & $2.04-2.25$ \\
$\mathrm{~K}$ & $0.35-0.39$ & $0.77-0.84$ \\
$\mathrm{~L}$ & $0.61-0.67$ & $1.09-1.2$ \\
M & $0.56-0.62$ & $1-1.1$ \\
\hline
\end{tabular}

${ }^{a}$ Dates obtained from non-parametric rate smoothing (NPRS) and semiparametric rate smoothing (penalized likelihood smoothing: PLS). The ages are in million years before present (Mya).

accelerated cytochrome $b$ sequence evolution rather than of ancient divergences, since cladogenesis would have occurred ca 1-2 Mya (see Table 4; similar results are obtained with Tajima's RRT-results not shown). All forms in this clade are uniformly brownish rats, which lack clear headspots (Fig. 3). The chromosomal F. micklemi radiation is characterised by extremely low levels of cytochrome b sequence divergence. The F. micklemi subtree topology basically consists of a trichotomy with three morphologically distinct groups. Firstly, there is the small, fawn-grey race with only an indication of a white mark on the head, collected at Chinyingi in the western Kasiji Plains. Second, there is a cluster of robust, brownish mole-rats from Watopa and Mayau, which are seemingly similar in size and shape to the Salujinga specimens. A third large cluster contains typical blesmoles (a misnomer for Cryptomys and Fukomys in view of the variation in external morphology) with clear headspots and brownish to black pelage (Fig. 3). The observed pattern of divergence appears to be congruent with several consecutive evolutionary bursts, which seem to have started in Northwestern Zambia (see below).

\subsection{Taxonomic implications}

Bathyergids exhibit considerable geographically structured morphological and genetical variation (Faulkes et al., 2004; Van Daele et al., 2006). In the past this fact triggered the description of many species and subspecies of bathyergids. Although this is not the place to revive the discussion about species concepts, it seems that the various species concepts can't be neatly applied to bathyergids and subterranean rodents in general (see e.g. Lessa, 2000). We advocate that species limits should be established using multiple sources of evidence which includes data from the molecular, cytogenetical and organismal levels (as opposed to e.g. Roberts, 1951). Traditional morphology based systematic studies of Fukomys (earlier synonym Cryptomys) yield no clear results because of the lack of clear morphological differences between species. This problem is best illustrated by Haymans' struggle to classify the species of both Fukomys and Cryptomys (in Ellerman et al., 1940).

The presently available information indicates that Fukomys contains more species than the 12 that are currently recognised. Within all major clades there are multiple examples that provide support for the hypothesis that a number of described chromosomal races represent valid sibling species, of which several with limited parapatric distributions. Unpublished experiments attempting to crossbreed different chromosomal races indicate that the chromosomal races tested so far appear to have developed both (ethological) premating and postmating mechanisms, which isolate these (presumptive) species (P. Van Daele, unpublished data; H. Burda personal comment). Within the $F$. mechowii clade, at least the Salujinga lineage may represent a so far undescribed species. These two potential species not only differ in body size but also have different skull shapes and a different karyotype (Van Daele et al., 2004), and represent separate cyt $b$ lineages. Chromosomal data are missing for the ambiguous Kinshasa (DRC) haplotype (originating from the Mbombo-Lumene National Park-DRC), but the external morphological features of the specimens of this population are typical $F$. mechowii (R.K. Kisasa, personal comment). The large mole-rat specimen from Chiundaponde (Zambia), collected in the vicinity of the type-locality of Georychus mellandi (Thomas, 1906) resembles $F$. mechowii in all aspects studied so far (external morphology, karyotype, cyt b) and should, therefore, be considered a synonym. Our data, combined with geometric morphometrical data (skull shape and size, Van Daele et al., 2006) reveal that the $F$. whytei clade contains genetically well differentiated taxa that are morphologically very similar. Therefore, the two currently recognised species within the northern Zambezian $F$. whytei clade, $F$. amatus and $F$. whytei may represent as many as 7 species (including Mzuzu). Species descriptions of these Northern Zambian, Tanzanian and Malawian taxa will have to await the analysis of topotypical material from the geographically proximate $C$. $h$. occlusus (Allen and Loveridge, 1951) described from Kigogo, Tanzania. Overall the $F$. whytei clade is characterised by a brown pelage colour and the absence of clear headspots or the infrequent occurrence of small headspots. Therefore, future studies should take into account that many museum specimens (typically from outside the distribution range of the $F$. whytei clade) that were assigned on morphological grounds to $F$. amatus or $F$. whytei probably belong to taxa in the parapatrically distributed $F$. micklemi clade. Within the $F$. micklemi clade the taxonomical picture is muddled. $F$. micklemi is the senior specific name available for representatives of that clade. Further systematic studies are required to determine the specific status and the validity of taxonomic assignment of $F$. anselli and $F$. kafuensis. 


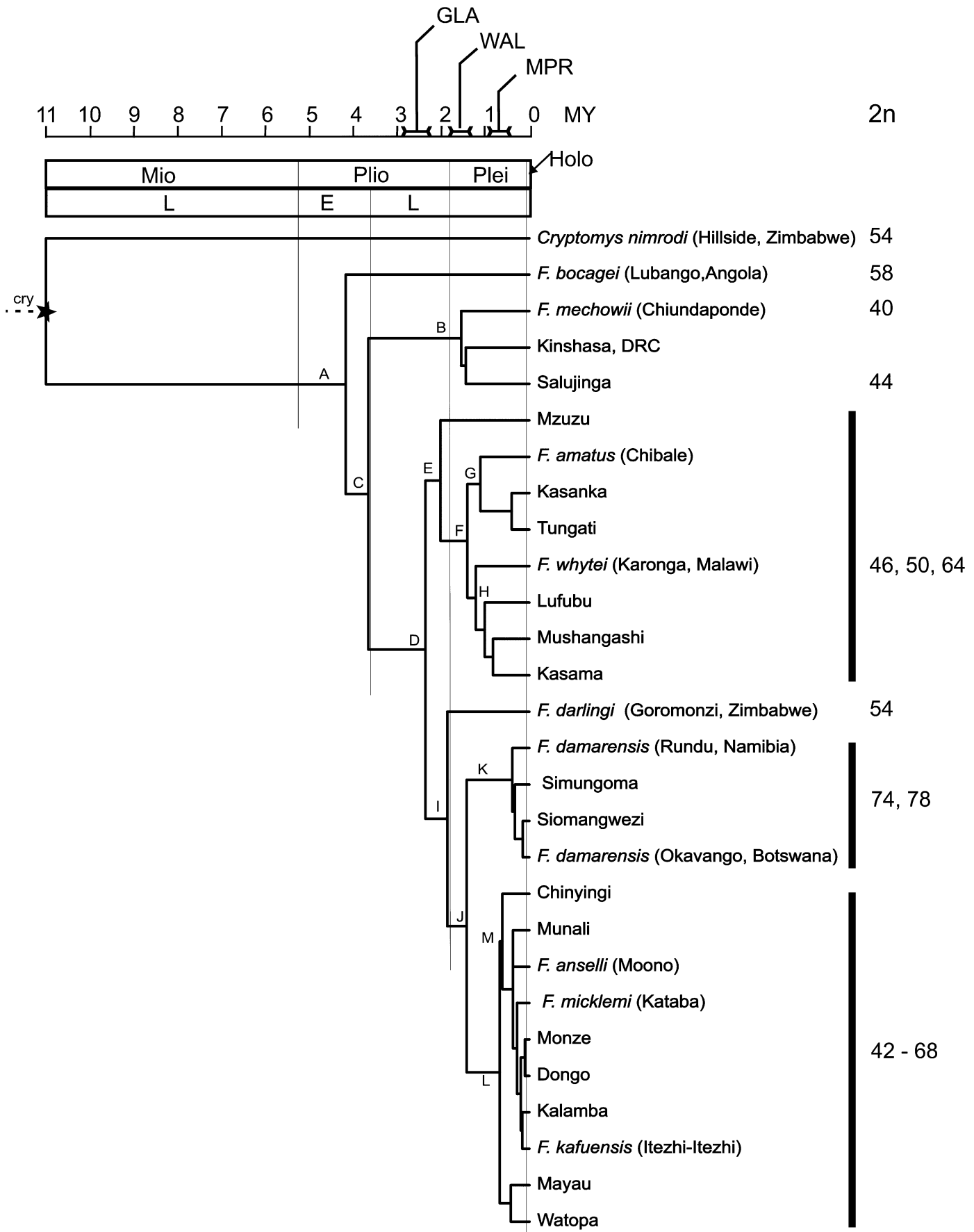

Fig. 7. Dated phylogenetic tree of Zambezian Fukomys obtained after semiparametric rate smoothing (penalized likelihood smoothing: PLS) in R8s. Letters on the nodes refer to Table 3. The time scale shows ages in million years before present Mya. Mio, miocene; Plio, pliocene; Plei, pleistocene; Holo, holocene; L, late; E, early; GLA, onset of northern glaciations; WAL, development of Walker circulation; MPR, mid pleistocene revolution.

Table 4

Results of a Two Cluster test showing significant heterogeneity between major clades

\begin{tabular}{llc}
\hline Cluster & \multicolumn{2}{c}{ delta } \\
\hline A & B & \\
\hline F. damarensis clade & $<$ F. micklemi & 0.006243 \\
F. darlingi clade & $<$ F. damarensis, F. micklemi clades & 0.00725 \\
F. whytei clade & $>$ F. darlingi, F. damarensis, F. micklemi clades & 0.01785 \\
\hline
\end{tabular}

\footnotetext{
${ }^{* *}$ Values are significant at the $1 \%$ level.
} 
No topotypical material has been analysed for C. molyneuxi, possibly a senior synonym of $F$. anselli. There is only limited evidence that supports splitting $F$. micklemi (the senior synonym) and F. kafuensis (Burda et al., 1999). It should be stressed that the diagnostic value of chromosomal markers for the separation and identification of putative Fukomys species remains to be tested.

\subsection{Biogeographical and temporal implications}

The current distribution of the different phylogroups correlates well with the geomorphological structuring and vegetational division of the Zambezian area (Fig. 11 in Van Daele et al., 2004; Fig 1). In spite of our efforts to collect on the Zaire River/Zambezi River watershed in Zambia, no haplotypes from the $F$. bocagei clade were recorded. $F$. bocagei seems to be the earliest divergence in the Zambezian mole-rats. This could be an indication of a western origin of the Zambezian group. This is further supported by both the coincidence of our divergence time estimate and the geomorphological history of South-central Africa. The F. mechowii clade is widespread along the Zaire River/Zambezi River watershed and in the Guineo-Congolean savannahs bordering the Guineo-Congolean forest. Based on our calibration of the molecular clock, we estimate that the clade diverged at the end of the Pliocene when dispersion along the Zaire/Zambezi watershed and across the Guineo-Congolean belt would have been possible. (See Fig. 5 in Van Daele et al., 2007). If our molecular clock is correct then the radiations within the $F$. micklemi and $F$. damarensis clades are surprisingly young, which implies that they are the result of rapid consecutive cladogenetic events since the early Pleistocene. Elsewhere we explained the coincidence of the distribution of chromosomal races with the geomorphological repatterning of the Zambezian area (Van Daele et al., 2004). That historical model, based mainly on riversystem reconfigurations, helps to explain the divergence between the major phylogroups. We suggest that climatic fluctuations may have played a substantial role in the diversification within each phylogroup. Associated vegetation shifts, leading to spatial fragmentation of populations, would have favoured the fixation of chromosomal rearrangements (Wang and Lan, 2000; Rieseberg, 2001; Veyrunes et al., 2005). Major steps in the evolution of Fukomys appear to coincide with shifts to more arid, open habitat conditions near 2.7-2.5, 1.9-1.7, and 0.95-0.7 Mya with alternating climatic shifts that lead to humid conditions and habitat fragmentation (see, respectively, Haug and Tiedemann, 1998; Ravelo et al., 2004; Berger and Jansen, 1994). The chronogram (Fig. 7) reveals that the observed cladogenetic events during the Plio-Pleistocene within the $F$. mechowii, $F$. whytei, $F$. damarensis and $F$. micklemi clades appear to coincide with climatically mediated speciation bursts in other savannah dwelling mammals, including hominids (Ducroz et al., 1998; Bobe and Behrensmeyer, 2004; Trauth et al., 2005; Veyrunes et al., 2005).

\subsection{Chromosomal radiations}

Although we find several cytotypes within each major clade for which several topotypes could be karyotyped, we do not detect a clear pattern of chromosomal evolution. It is remarkable that within the $F$. whytei, $F$. damarensis and $F$. micklemi clades, we observed more chromosomal races and subdivisions of chromosomal races in areas with a particularly affected geomorphology, such as capture elbows of the Zambezi, Kafue and Chambeshi rivers. Possibly the geomorphological disturbances in these areas have fuelled cladogenesis in these mole-rats. The combination of suitable alluvial grounds for the dispersal of mole-rats and fluctuating water levels in these streams (correlated with climatic shifts) may have resulted in the fragmentation of mole-rat populations and their differentiation through allopatric and peripatric speciation. Similar events have been suggested to have affected the speciation rates in small antelopes (Cotterill, 2003). However, when we plot the karyotypical data on the molecular phylogeny, a differential pattern of chromosomal evolution between the clades emerges. This difference is most striking when we compare the $F$. micklemi and $F$. whytei clades. The karyotypically hyper-diverse $F$. micklemi clade shows low levels of cytochrome $b$ sequence divergence in agreement with the results from more limited datasets of other genes (op. cit.). Within the $F$. whytei clade we find a more conservative pattern of chromosomal diversification, while the levels of sequence divergence are much higher then in the F. micklemi clade. There are different plausible explanations for this phenomenon. Firstly, structural chromosomal rearrangements may play an important role in initiating species divergence (White, 1978), while mutations in mitochondrial DNA sequences will accumulate over longer periods of time. In addition, it has been suggested that chromosomal rearrangements may have a disturbing influence on the functioning of co-adapted genome complexes, leading to subtle, non-lethal disturbance of developmental processes (Graham, 1992). According to that scenario, directional selection would optimize gene groups' function and filter out unfit chromosome combinations over time. It is tempting to suggest that the older $F$. whytei lineage may represent a more stable chromosomal state, and that in the process a number of unfit diploid combinations have disappeared. In contrast, the more recent $F$. micklemi radiation possibly represents a younger stage with a high number of chromosomal rearrangements, of which many will be selected against over a longer time span. Similar patterns have been observed in other taxa (cf. Nevo et al., 2001 for Spalax; Veyrunes et al., 2005 for Nannomys; Castiglia et al., 2006 for Arvicanthis).

Until karyotypical evolutionary trends are better understood, it is premature to decide whether demographic, historical or ecological models (see e.g. Patton, 1990; Nevo et al., 1995; Nevo, 1999) are more suitable to explain the observed differential evolutionary trends in different clades. While we have discussed the (historical) geographic setting 
in which cladogenesis of Fukomys took place, we lack evidence on demographic processes that have shaped the evolutionary trajectories of these populations. Nor do we have reliable evidence on the possible role of hybridisation in raciation and speciation of mole-rats, as has been suggested before (Harrison, 1993). This may be important in Fuko$m y s$ as evidenced by the odd diploid $(2 n=45)$ race originating from the vicinity of Lochinvar, Zambia (Van Daele et al., 2004). However, in order to understand the evolutionary mechanisms that shape the chromosomal evolution within each phylogroup, we will have to develop and use differential staining techniques (cf. Deuve et al., 2006) to map the observed chromosomal rearrangements, and fathom their functional, genomic consequences. In addition, it is clear that more sequences, including other genes, are required to obtain more detailed phylogeographical patterns within each of the major clades.

\section{Acknowledgments}

For assistance in collecting specimens in the field the authors are extremely grateful to E. Sikaboa, G. Sikaulu, S. Stoops and F. Van Daele. We are especially indebted to H. Burda, P. Dammann, R. Honeycutt and C. Ingram for sending specimens. Special thanks to V. Katanekwa and ZAWA for field support and providing permits. We like to thank Tine Dillen, G. Borgonie, A. Huysseune and A. Vierstraete for help with the molecular logistics.

\section{References}

Aguilar, G.H., 1993. The karyotype and taxonomic status of Cryptomys hottentotus darlingi (Rodentia, Bathyergidae). S. Afr. J. Zool. 28, 201204.

Barnett, M., Bennett, N.C., Telford, S.R., Jarvis, J.U.M., 2003. Foraging in the subterranean social Damaraland mole-rat, Cryptomys damarensis: an investigation into size-dependent geophyte utilization and foraging patterns. Can. J. Zool. 81, 743-752.

Bennett, N.C., Faulkes, C.G., 2000. African Mole-rats: Ecology and Eusociality. Cambridge University Press, Cambridge.

Berger, W.H., Jansen, E., 1994. Mid-Pleistocene climate shift — the Nansen connection. In: Johannessen, O.M., Muench, R.D., Overland, J.E. (Eds.), The Polar Oceans and their Role in Shaping the Global Environment. American Geophysical Union, Washington, DC, pp. 295-311.

Bobe, R., Behrensmeyer, A.K., 2004. The expansion of grassland ecosystems in Africa in relation to mammalian evolution and the origin of the genus Homo. Palaeogeogr. Palaeoclimatol. Palaeoecol. 207, 399-420.

Buffenstein, R., 2005. The naked mole-rat: a new long-living model for ageing research. J. Gerontol. 60A, 1369-1377.

Bruckmann, G., Burda, H., 1997. Hearing in blind subterranean Zambian mole-rats (Cryptomys sp.): collective behavioural audiogram in a highly social rodent. J. Comp. Physiol. A-Sens. Neur. Behav. Physiol. 181, 83-88.

Burda, H., 2001. Determinants of the distribution and radiation of African mole-rats (Bathyergidae, Rodentia): ecology or geography? In: Denys, C., Granjon, L., Poulet, A. (Eds.), African Small Mammals, IRD Editions. Collection Colloques et séminaires, Paris, pp. 261-277.

Burda, H., Zima, J., Scharff, A., Macholán, M., Kawalika, M., 1999. The karyotypes of Cryptomys anselli sp nova and Cryptomys kafuensis $s p$ nova: new species of the common mole-rat from Zambia (Rodentia, Bathyergidae). Int. J. Mamm. Biol. 64, 36-50.

Burda, H., Honeycutt, R.L., Begall, S., Locker-Grütjen, O., Scharff, A., 2000. Are naked and common mole-rats eusocial and if so, why? Behav. Ecol. Sociobiol. 47, 293-303.

Burda, H., Sumbera, R., Chitaukali, W.N., Dryden, G.L., 2005. Taxonomic status and remarks on ecology of the malawian mole-rat Cryptomys whytei (Rodentia, Bathyergidae). Acta Theriologica 50 , 529-536.

Burland, T.M., Bennett, N.C., Jarvis, J.U.M., Faulkes, C.G., 2002. Eusociality in African mole-rats: new insights from patterns of genetic relatedness in the Damaraland mole-rat (Cryptomys damarensis). Proc. R Soc. Lond. B Biol. Sci. 269, 1025-1030.

Burland, T.M., Bennett, N.C., Jarvis, J.U.M., Faulkes, C.G., 2004 Colony structure and parentage in wild colonies of co-operatively breeding Damaraland mole-rats suggest incest avoidance alone may not maintain reproductive skew. Mol. Ecol. 13, 2371-2379.

Castiglia, R., Bekele, A., Makundi, R., Oguge, N., Corti, M., 2006. Chromosomal diversity in the genus Arvicanthis (Rodentia, Muridae) from East Africa: A taxonomic and phylogenetic evaluation. J. Zool. Syst. Evol. Res. 44, 223-235.

Chitaukali, W.N., Burda, H., Kock, D., 2001. On small mammals of the Nyika Plateau, Malawi. In: Denys, C., Granjon, L., Poulet, A. (Eds.), African Small Mammals, IRD Editions. Collection Colloques et séminaires, Paris, pp. 415-426.

Cotterill, F.P.D., 2003. Geomorphological influences on vicariant evolution in some African mammals in the Zambezi Basin: some lessons for conservation. In: Plowman, A.B. (Ed.), Proceedings of the Ecology and Conservation of Mini-antelope: An International Symposium on Duiker and Dwarf Antelope in Africa. Filander Verlag, Fürth, pp. 1158

Dammann, P., Burda, H., 2006. Sexual activity and reproduction delay ageing in a mammal. Curr. Biol. 16, 117-118.

Deuve, J.L., Bennett, N.C., O'Brien, P.C.M., Ferguson-Smith, M.A., Faulkes, C.G., Britton-Davidian, J., Robinson, T.J., 2006. Complex evolution of $\mathrm{x}$ and $\mathrm{y}$ autosomal translocations in the Giant mole-rat, Cryptomys mechowi (Bathyergidae). Chromosome Res. 14, 681-691.

Ducroz, J.F., Volobouev, V., Granjon, L., 1998. A molecular perspective on the systematics and evolution of the genus Arvicanthis (Rodentia, Muridae): inferences from complete cytochrome $b$ gene sequences. Mol. Phylogenet. Evol. 10, 104-117.

Ellerman, J.R., Hayman, R.W., Holt, G.W.C., 1940. The families and genera of living rodents. Trustees of the British Museum (Natural History), London.

Farris, J.S., 1969. A successive approximations approach to character weighting. Syst. Zool. 18, 374-385.

Farris, J.S., 1989. The retention index and the rescaled consistency index. Cladistics 5, 417-419.

Faulkes, C.G., Bennett, N.C., 2001. Family values: group dynamics and social control of reproduction in African mole-rats. Trends Ecol. Evol. $16,184-190$.

Faulkes, C.G., Bennett, N.C., Bruford, M.W., O' Brien, H.P., Aguilar, G.H., Jarvis, J.U.M., 1997. Ecological constraints drive social evolution in the African mole-rats. Proc. R Soc. Lond. B Biol. Sci. 264, 1619-1627.

Faulkes, C.G., Verheyen, E., Verheyen, W., Jarvis, J.U.M., Bennett, N.C., 2004. Phylogeographical patterns of genetic divergence and speciation in African mole-rats (family: Bathyergidae). Mol. Ecol. 13, 613-629.

Felsenstein, J., 1981. Evolutionary Trees From DNA-Sequences-a Maximum-Likelihood Approach. J. Mol. Evol. 17, 368-376.

Felsenstein, J., 1985. Confidence limits on phylogenies: an approach using the bootstrap. Evolution 39, 783-791.

Filippucci, M.G., Burda, H., Nevo, E., Kocka, J., 1994. Allozyme divergence and systematics of common mole-rats (Cryptomys, Bathyergidae, Rodentia) from Zambia. Int. J. Mamm. Biol. 59, 42-51.

Ganem, G., Bennett, N.C., 2004. Tolerance to unfamiliar conspecifics varies with social organization in female African mole-rats. Physiol. Behav. 82, 555-562. 
Graham, J.H., 1992. Genomic coadaptation and developmental stability in hybrid zones. Zoologica Fennica 191, 121-131.

Greeff, J.M., Bennett, N.C., 2000. Causes and consequences of incest avoidance in the cooperatively breeding mole-rat, Cryptomys darlingi (Bathyergidae). Ecol. Lett. 3, 318-328.

Harrison, R.G., 1993. Hybrids and hybrid zones. In: Harrison, R.G. (Ed.), Hybrid Zones and the Evolutionary Process. Oxford University Press, New York, pp. 3-12.

Haug, G.H., Tiedemann, R., 1998. Effect of the formation of the isthmus of Panama on Atlantic Ocean thermohaline circulation. Nature 393, 673-676.

Hazell, R.W.A., Bennett, N.C., Jarvis, J.U.M., Griffin, M., 2000. Adult dispersal in the co-operatively breeding Damaraland mole-rat (Cryptomys damarensis): a case study from the Waterberg region of Namibia. J. Zool. (Lond) 252, 19-25.

Honeycutt, R.L., Nelson, K., Schlitter, D.A., Sherman, P.W., 1991. Genetic variation within and among populations of the naked molerat: evidence from nuclear and mitochondrial genomes. In: Sherman, P.W., Jarvis, J.U.M., Alexander, R.D. (Eds.), The Biology of the Naked Mole-rat. Princeton University Press, Princeton, pp. 195-208.

Ingram, C.M., Burda, H., Honeycutt, R.L., 2004. Molecular phylogenetics and taxonomy of the African mole-rats, genus Cryptomys and the new genus Coetomys Gray, 1864. Mol. Phylogenet. Evol. 31, 997-1014.

Janse Van Rensburg, L., Chimimba, C.T., Van Der Merwe, M., Schoeman, A.S., Bennett, N.C., 2004. Relative age and reproductive status in Cryptomys Hottentotus Pretoriae (Rodentia: Bathyergidae) from South Africa. J. Mammal. 85, 1225-1232.

Jarvis, J.U.M., Bennett, N.C., 1993. Eusociality has evolved independently in 2 genera of bathyergid mole-rats-but occurs in no other subterranean mammal. Behav. Ecol. Sociobiol. 33, 253-260.

Jarvis, J.U.M., Bennett, N.C., Spinks, A.C., 1998. Food availability and foraging by wild colonies of Damaraland mole-rats (Cryptomys damarensis): implications for sociality. Oecol. 113, 290-298.

Jarvis, J.U.M., Oriain, M.J., Bennett, N.C., Sherman, P.W., 1994. Mammalian eusociality - a family affair. Trends Ecol. Evol. 9, 47-51.

Kock, D., Ingram, C.M., Frabotta, L.J., Honeycutt, R.L., Burda, H., 2006. On the Nomenclature of Bathyergidae and Fukomys N. Gen. (Mammalia: Rodentia). Zootaxa 1142, 51-55.

Kumar, S., Tamura, K., Nei, M., 2004. Mega3: integrated software for molecular evolutionary genetics analysis and sequence alignment. Brief. Bioinform. 5, 150-163.

Lessa, E.P., 2000. The evolution of subterranean rodents: a synthesis. In: Lacey, E.A., Patton, J.L., Cameron, G.N. (Eds.), Life Underground. The Biology of Subterranean Rodents. University of Chicago Press, Chicago, pp. 389-420.

Macholán, M., Scharff, A., Burda, H., Zima, J., Grütjen, O., 1998. The karyotype and taxonomic status of Cryptomys amatus (Wroughton, 1907) from Zambia (Rodentia, Bathyergidae). Int. J. Mammal. Biol. 63, 186-190.

Nemec, P., Altmann, J., Marhold, S., Burda, H., Oelschlager, H.H.A., 2001. Neuroanatomy of magnetoreception: the superior colliculus involved in magnetic orientation in a mammal. Science 294, 366-368.

Nevo, E., 1999. Mosaic Evolution of Subterranean Mammals: Regression, Progression and Global Convergence. Oxford University Press, Oxford.

Nevo, E., Filippucci, M.G., Redi, C., Simson, S., Heth, G., Beiles, A., 1995. Karyotype and genetic evolution in speciation of subterranean mole-rats of the genus spalax in Turkey. Biol. J. Lin. Soc. 54, 203-229.

Nevo, E., Ivanitskaya, E., Beiles, A., 2001. Adaptive radiation of blind subterranean mole rats. Backhuys Ltd, Leiden.

Page, R.D.M., 1996. TREEVIEW: an application to display phylogenetic trees on personal computers. Comp. Appl. Biosci. 12, 357-358.

Patton, J.L., 1990. Geomyid evolution: the historical, selective, and random basis for divergence patterns within and among species. In: Nevo, E., Reig, S. (Eds.), Evolution of Subterranean Mammals at the Organismal and Molecular Levels. Wiley, Liss, New York, pp. 49-70.

Posada, D., Crandall, K.A., 1998. Modeltest: testing the model of DNA substitution. Bioinformatics 14, 817-818.
Ravelo, A.C., Andreasen, D.H., Lyle, M., Lyle, A.O., Wara, M.W., 2004. Regional climate shifts caused by gradual global cooling in the Pliocene epoch. Nature 429, 263-267.

Rieseberg, L.H., 2001. Chromosomal rearrangements and speciation. Trends Ecol. Evol. 16, 351-358.

Roberts, A., 1951. The Mammals of South Africa. Trustees of 'the mammals of South Africa' book fund, Johannesburg.

Ronquist, F., Huelsenbeck, J.P., 2003. Mrbayes 3: Bayesian phylogenetic inference under mixed models. Bioinformatics 19, 1572-1574.

Sanderson, M.J., 1997. A nonparamateric approach to estimating divergence times in the absence of rate constancy. Mol. Biol. Evol. $14,1218-1231$.

Sanderson, M.J., 2003. R8s: inferring absolute rates of molecular evolution of divergence times in absence of a molecular clock. Bioinformatics 19, 301-302.

Sanderson, M.J., 2004. R8s, version 1.70. User's manual.

Scantlebury, M., Speakman, J.R., Oosthuizen, M.K., Roper, T.J., Bennett, N.C., 2006. Energetics reveals physiologically distinct castes in a eusocial mammal. Nature 440, 795-797.

Spinks, A.C., Bennett, N.C., Jarvis, J.U.M., 2000a. A comparison of the ecology of two populations of the common mole-rat, Cryptomys hottentotus hottentotus: the effect of aridity on food, foraging and body mass. Oecologia 125, 341-349.

Spinks, A.C., Jarvis, J.U.M., Bennett, N.C., 2000b. Patterns of philopatry and dispersal in two common mole-rat populations: implications for the evolution of mole-rat sociality. J. Animal Ecol. 69, 224-234.

Swofford, D.L., 2002. PAUP* Phylogenetic Analysis using Parsimony (*and other methods). Version 4. Sinauer Associates, Sunderland, Massachusetts

Swofford, D.L., Sullivan, J., 2003. Phylogeny inference based on parsimony and other methods using PAUP* In: Salemi, M., Vandamme, A.-M. (Eds.), The Phylogenetic Handbook. A Practical Approach to DNA and Protein Phylogeny. Cambridge University Press, Cambridge, pp. 160-206.

Tajima, F., 1993. Simple methods for testing the molecular evolutionary clock hypothesis. Genetics 135, 599-607.

Takezaki, N., Rzhetsky, A., Nei, M., 1995. Phylogenetic test of the molecular clock and linearized trees. Mol. Biol. Evol 12, 823833 .

Thompson, J.D., Higgins, D.G., Gibson, T.J., 1994. Clustal-W-improving the sensitivity of progressive multiple sequence alignment through sequence weighting, position-specific gap penalties and weight matrix choice. Nucleic Acids Res. 22, 4673-4680.

Trauth, M.H., Maslin, M.A., Deino, A., Strecker, M.R., 2005. Late Cenozoic moisture history of East Africa. Science 309, 2051-2053.

Van Daele, P.A.A.G., Dammann, P., Meier, J.L., Kawalika, M., Van De Woestijne, C., Burda, H., 2004. Chromosomal diversity in mole-rats of the genus Cryptomys Rodentia: Bathyergidae) from the Zambezian region: with descriptions of new Karyotypes. J. Zool. (Lond.) 264, 317-326.

Van Daele, P.A.A.G., Verheyen, E., Corkery, I., Adriaens, D., 2006. Trends in skull morphology in relation to differential molecular evolution in African mole-rats of the chromosomally hyperdivers genus Fukomys (Bathyergidae, Rodentia) from the Zambezian region. It. J. Mammal., supp., 143.

Van Daele, P.A.A.G., Faulkes, C.G., Verheyen, E., Adriaens, D., 2007. African mole-rats Bathyergidae): a complex radiation in tropical soils. In: Begall, S., Burda, H., Schleich, C.E. (Eds.), Subterranean Rodents: News from Underground. Springer-Verlag, Heidelberg.

Veyrunes, F., Britton-Davidian, J., Robinson, T.J., Calvet, E., Denys, C., Chevret, P., 2005. Molecular phylogeny of the African pygmy mice, subgenus Nannomys (Rodentia, Murinae, Mus): implications for chromosomal evolution. Mol. Phylogenet. Evol. 36, 358-369.

Wang, W., Lan, H., 2000. Rapid and parallel chromosomal number reductions in muntjac deer inferred from mitochondrial DNA phylogeny. Mol. Biol. Evol. 17, 1326-1333.

White, M.J.D., 1978. Modes of speciation. Freeman, San Francisco. 